\title{
A study on Methicillin resistant Staphylococcus aureus mastitis in dairy cows
}

\author{
D. Chandrasekaran $^{1 *}$,P. Venkatesan ${ }^{2}$, K. G. Tirumurugaan ${ }^{2}$, A. P. Nambi ${ }^{1}$, P. S. Thirunavukkarasu ${ }^{1}$, \\ K. Kumanan ${ }^{2}$ and S.Vairamuthu ${ }^{3}$ \\ ${ }^{1}$ Department of Veterinary Clinical Medicine, Ethics and Jurisprudence, Madras Veterinary College, Tamil Nadu \\ Veterinary and Animal Sciences University, Chennai, INDIA \\ ${ }^{2}$ Department of Animal Biotechnology, Madras Veterinary College, Tamil Nadu Veterinary and Animal Sciences \\ University, Chennai, INDIA \\ ${ }^{3}$ Centralized Clinical Laboratory, Madras Veterinary College, Tamil Nadu Veterinary and Animal Sciences \\ University, Chennai, INDIA \\ *Corresponding author. E-mail: drchandrus@ yahoo.com
}

Received: June 29, 2014; Revised received: August 22, 2014 ; Accepted: September 18, 2014

\begin{abstract}
Methicillin-resistant Staphylococcus aureus (MRSA) poses a serious problem in dairy animals suffering from mastitis. The study was carried out to evaluate the incidence of Methicillin resistant $S$. aureus from clinical mastitis milk samples and their antibiotic resistance profile and characterised with respect to the molecular features that contributed to the resistance in these pathogens. Isolation and identification of Methicillin resistant $S$. aureus were performed from acute clinical mastitis samples. The isolates were tested using agar disc diffusion method for their antimicrobial susceptibility and modified resazurin assay micro dilution technique for MIC to 8 different antimicrobial drugs. A total of 235 clinical mastitis milk samples from dairy cows were cultured for incidence of $S$. aureus. Methicillin resistant S. aureus was isolated from a total of $12(44.25 \%)$ of the 116 S. aureus samples. Based on the antimicrobial sensitivity and MIC results, MRSA isolates were found sensitive to gentamicin, enrofloxcain, amoxicillin+sulbactam, ceftriaxone and resistant to amoxicillin, oxytetracycline, penicillin $\mathrm{G}$ and oxacillin. Most of MRSA isolates were found to be multi-drug resistant. MRSA alert kit test and mecA and blaZ target gene PCR were found to be useful in the confirmation of MRSA.
\end{abstract}

Keywords: Antibiotic susceptibility, Antimicrobial drug resistance, Bovine mastitis, MIC, mecA, MRSA, PCR blaZ, PVL gene

\section{INTRODUCTION}

Bovine mastitis, a multi-factorial disease, is characterized by physical, chemical and microbiological changes in the milk and pathological changes in the glandular tissue of udder (Radostits et al., 2008). Among the various pathogens that affect the bovine mammary gland Staphylococcus aureus is the most frequently (45-60 per cent) isolated pathogens and often results clinical or subclinical or chronic bovine mastitis. $S$. aureus is capable of producing several exo and endotoxins e.g coagulase and is also endowed with a capsule that makes it difficult to treat.

In the control of mastitis, the improper use of antimicrobial agents on dairy farm animals is a major concern as it leads to the emergence of resistant zoonotic bacterial pathogens (Piddock, 1996). The antibiotic-resistance of prevalent S.aureus strains is another serious concern besides the pathogenicity. The emergence of antibiotic-resistance in $S$. aureus from mastitic dairy animals has been shown in recent years. Beta-lactam antibiotics are frequently used in mastitis therapy and the resistance is due to the production of beta-lactamases and low -affinity penicillin-binding protein, PBP2A (Olsen et al., 2006)

Several strains of S.aureus isolated from mastitis case have been reported to show resistance against multiple antimicrobials such as penicillin-G, gentamicin, streptomycin, ampicillin, ciprofloxacin, oxytetracycline (Kumar et al., 2011). $\beta$-lactamase resistant penicillins such as methicillin and oxacillin are not used in dairy cows except for cloxacillin that is used in products for intramammary administration (Turutoglu et al., 2006). Among the resistance to commonly used antibiotics, resistance to this bacterium, methicillin (hence termed methicillin resistance $S$. aureus- MRSA) is a serious cause of concern in both human and animals (Witte et al., 2007). Bovine and human MRSA strains are epidemiologically related, which indicates transmission from either cow to human or human to cow possible (Juhász- Kaszanyitzky et al., 2007). This strain is negative for the Panton Valentine Leucocidin (PVL) genes, which differentiates it from community associated MRSA ST 1, which is positive for PVL genes (Vandenesch et al., 2003). PVL genes have been associated with community-acquired MRSA (CA- 
MRSA) rather than hospital-linked human MRSA (HA -MRSA) strains (Blaine et al., 2010). The genes encoding for PVL toxin are shown to be responsible for severe necrotic lesions of the skin and soft tissues and are predominantly present in CA-MRSA (Rankin et al., 2005).

Data on the prevalence of these resistant strains is lacking and this study was undertaken to look at the incidence of Methicillin resistant $S$. aureus from clinical mastitis milk samples and their antibiotic resistance profile. These organisms were also characterised with respect to the molecular features that contributed to the resistance in these pathogens.

\section{MATERIALS AND METHODS}

Collection, isolation and identification of $S$. aureus: Two hundred and thirty five milk samples from acute mastitis cases from Large Animal Clinic Medicine Unit of Madras Veterinary College Teaching Hospital and six dairy farms in Coimbatore district. The guidelines of National Mastitis Council (NMC) were followed for sample collection, transportation, culture and isolation of Staphylococci. A total of $116 \mathrm{~S}$. aureus isolates were characterized by their growth on blood agar and mannitol salt agar and the results for catalase and coagulase (CLSI, 2008).

Profiling the antibiotic susceptibility and resistance: Antimicrobial susceptibility testing was carried out at equivalent to $0.5 \mathrm{McFarland}$ turbidity standard by agar disc diffusion method on Mueller-Hinton agar plates following the guidelines of CLSI (CLSI, 2008). Commercially available antibiotic discs (Himedia, Mumbai) were used in the study viz., Enrofloxacin (EX $10 \mathrm{mcg}$ ), Amoxicillin+sulbacatm (AMS $15 \mathrm{mcg}$ ), Amoxicillin (AMX $10 \mathrm{mcg}$ ), Gentmicin (GEN 10 mcg), Ceftriaxone (CTR $30 \mathrm{mcg}$ ), Oxytetracycline (TE $30 \mathrm{mcg}$ ) and Penicillin G (P 10 units) and Oxacillin (OX $5 \mathrm{mcg}$ ). The sizes of the zone of inhibition were recorded and interpreted as either bacteria were susceptible or resistant to the exposed agent (Table 1).

Methicillin resistant $S$. aureus : MSRA Alert ${ }^{\mathrm{TM}} \mathrm{Kit}$ (Hi-media, Mumbai) was used for confirmation of Methicillin Resistant Staphylococcus aureus. The inoculum was prepared from material picked up with sterile loop from atleast 4-5 well isolated colonies on mannitol salt agar of similar type, inoculated into $3 \mathrm{ml}$ sterile nutrient broth and incubated at $37^{\circ} \mathrm{C}$. This broth sample was inoculated into the dissolved in the MSRA Alert ${ }^{\mathrm{TM}}$ and was incubated at $35^{\circ} \mathrm{C}$ without shaking. The MRSA Alert test tubes were examined up to 24 hours for the presence of a clot and colour change in the medium from red to yellow indicated positive result (Selepak and Witebsky, 1985).

Minimum inhibitory concentration (MIC): The minimum inhibitory concentrations of different antibiotics for MRSA isolates were determined by modified resazurin assay microdilution technique (Sarker et al., 2007). The MIC panels consisted of dehydrated antimicrobial agents: amoxicillin, ceftriaxone, enrofloxacin, gentamicin, pencillin, oxytetracycline, amoxicillin + sulbactam and oxacillin in 96-well $\mathrm{U}$ bottom microtiter plates and performed in accordance with the guidelines established by the CLSI (CLSI, 2008). The lowest concentration of antibiotic that resulted in complete inhibition of visible growth and did not produce any turbidity was taken as the MIC end point (Table 2).

Molecular characterization of the $S$. aureus and their resistance genes: A single colony was from the selective agar was suspended in nuclease free water for the different isolates and lysed by boiling for 10 minutes and the lysate was stored at $-20^{\circ} \mathrm{C}$ until use. The lysate were used in a PCR reaction with primers targeting the gap gene(Yugueros et al., 2001) to confirm these isolates to be $S$. aureus. The PCR amplicons from some of the samples were sequenced and analysed by BLAST search to confirm their identity. On confirmation of these isolates to be $S$. aureus PCR was performed in these lysates to detect the mecA and blaZ genes that contribute to methicillin resistance in these bacteria and also with primers to determine the PVL genes that contribute to the transmission of these isolates across species. The details of primers used in the study are presented in Table 3.

PCR amplification was performed in a total reaction volume of $25 \mu \mathrm{l}$. The reaction mixture contained 12.5 $\mu l$ of the master mix, $20 \mathrm{pmol}$ of the forward and reverse primer and $15 \mu \mathrm{l}$ of the test lysate. The amplification profile for the PCR for detection of the different genes were $94^{\circ} \mathrm{C} 5 \mathrm{~min} ; 35$ cycles of $95^{\circ} \mathrm{C}$ for $45 \mathrm{sec}, 55^{\circ} \mathrm{C}$ for $1 \mathrm{~min}, 72^{\circ} \mathrm{C}$ for $1 \mathrm{~min}$; final extension of $72^{\circ} \mathrm{C}$ for $7 \mathrm{~min}$. The PCR products were separated by gel electrophoresis in 1.5 per cent agarose gel and visualized staining with ethidium bromide.

\section{RESULTS}

A total of 235 clinical mastitis milk samples revealed 116 samples positive for $S$. aureus, of which 12 samples (10.34\%) were MRSA.

Bacterial cultures (Staphylococci) from mastitis samples were obtained on blood agar and mannitol salt agar plates. The colonies of haemolytic staphylococci were smooth, circular, moist, 1-2 $\mathrm{mm}$ in diameter, pinhead, raised, convex having entire margins and golden yellow in colour. Standard tests used for biochemical characterization of all the isolates obtained from mastitis samples confirmed the isolates as $S$. aureus.

Profiling the antibiotic susceptibility and resistance: MRSA showed maximum sensitivity to enrofloxacin and amoxicillin and sulbactam (75 per cent) each, gentamicin (33.3 per cent) and ceftriaxone (58.3 per cent) (Table 1). The isolates showed highest resistance to methicillin (100 per cent), amoxicillin (91.7 per cent), followed by penicillin G (83.3 per 
Table 1. Antibiotic susceptibility profile determined by agar disc diffusion method for MRSA isolates.

\begin{tabular}{ccccccccc}
\hline Isolates & Gen & OTC & Am+Su & Ceft & Enro & Amox & Pen & Oxa \\
\hline 1 & $\mathrm{R}$ & $\mathrm{R}$ & $\mathrm{S}$ & $\mathrm{R}$ & $\mathrm{S}$ & $\mathrm{R}$ & $\mathrm{R}$ & $\mathrm{R}$ \\
2 & $\mathrm{R}$ & $\mathrm{S}$ & $\mathrm{S}$ & $\mathrm{R}$ & $\mathrm{R}$ & $\mathrm{S}$ & $\mathrm{S}$ & $\mathrm{R}$ \\
3 & $\mathrm{R}$ & $\mathrm{S}$ & $\mathrm{S}$ & $\mathrm{R}$ & $\mathrm{S}$ & $\mathrm{R}$ & $\mathrm{R}$ & $\mathrm{R}$ \\
4 & $\mathrm{~S}$ & $\mathrm{R}$ & $\mathrm{S}$ & $\mathrm{S}$ & $\mathrm{S}$ & $\mathrm{R}$ & $\mathrm{R}$ & $\mathrm{R}$ \\
5 & $\mathrm{R}$ & $\mathrm{S}$ & $\mathrm{R}$ & $\mathrm{R}$ & $\mathrm{S}$ & $\mathrm{R}$ & $\mathrm{R}$ & $\mathrm{R}$ \\
6 & $\mathrm{R}$ & $\mathrm{S}$ & $\mathrm{S}$ & $\mathrm{S}$ & $\mathrm{R}$ & $\mathrm{R}$ & $\mathrm{R}$ & $\mathrm{R}$ \\
7 & $\mathrm{~S}$ & $\mathrm{R}$ & $\mathrm{R}$ & $\mathrm{R}$ & $\mathrm{S}$ & $\mathrm{R}$ & $\mathrm{R}$ & $\mathrm{R}$ \\
8 & $\mathrm{~S}$ & $\mathrm{R}$ & $\mathrm{S}$ & $\mathrm{S}$ & $\mathrm{S}$ & $\mathrm{R}$ & $\mathrm{S}$ & $\mathrm{R}$ \\
9 & $\mathrm{R}$ & $\mathrm{R}$ & $\mathrm{R}$ & $\mathrm{R}$ & $\mathrm{S}$ & $\mathrm{R}$ & $\mathrm{R}$ & $\mathrm{R}$ \\
10 & $\mathrm{R}$ & $\mathrm{R}$ & $\mathrm{S}$ & $\mathrm{R}$ & $\mathrm{S}$ & $\mathrm{R}$ & $\mathrm{R}$ & $\mathrm{R}$ \\
11 & $\mathrm{R}$ & $\mathrm{S}$ & $\mathrm{S}$ & $\mathrm{S}$ & $\mathrm{R}$ & $\mathrm{R}$ & $\mathrm{R}$ & $\mathrm{R}$ \\
12 & $\mathrm{~S}$ & $\mathrm{R}$ & $\mathrm{S}$ & $\mathrm{S}$ & $\mathrm{S}$ & $\mathrm{R}$ & $\mathrm{R}$ & $\mathrm{R}$ \\
\hline
\end{tabular}

$\mathrm{R}=$ Resistant, $\mathrm{S}=$ Susceptible; Gen $=$ Gentamicin, OTC $=$ Oxytetracycline, Am+Su = Amoxicillin+Sulbactam, Ceft $=$ Ceftriaxone, Enro $=$ Enrofloxacin, Pen $=$ Penicillin G and Oxa $=$ Oxacillin

Table 2. Minimum inhibitory concentrations (MIC) of drugs against MRSA $(n=12)$ isolated from udder of cows.

\begin{tabular}{|c|c|c|c|c|c|c|c|c|c|c|c|c|}
\hline \multicolumn{13}{|c|}{$\operatorname{MIC}(\mu \mathrm{g} / \mathrm{ml}) \quad(\mathrm{n}=12)$} \\
\hline & 125 & 62.5 & 31.25 & 15.62 & 7.8 & 3.9 & 1.95 & 0.97 & 0.48 & $\begin{array}{l}\text { MIC } \\
\text { range }\end{array}$ & $\mathrm{MIC}_{50}$ & $\mathrm{MIC}_{90}$ \\
\hline Gentamicin & 33.3 & 25 & 16.7 & - & 8.3 & 8.3 & 8.3 & - & - & $1.95-125$ & 31.25 & 125 \\
\hline Oxytetracycline & 25 & 41.7 & 16.7 & - & - & 8.3 & 8.3 & - & - & $1.95-125$ & 62.25 & 125 \\
\hline Ceftriaxone & 16.7 & 33.3 & 33.3 & - & 8.3 & 8.3 & - & - & - & $3.9-125$ & 62.25 & 62.5 \\
\hline Enrofloxacin & - & 16.7 & 16.7 & 16.7 & 8.3 & 25 & 8.3 & - & 8.3 & $0.48-62.5$ & 15.62 & 62.5 \\
\hline Amoxicillin & 33.3 & 50 & 16.7 & - & - & - & - & - & - & $31.25-125$ & 62.5 & 125 \\
\hline Pencillin G & 33.3 & 41.7 & 25 & - & - & - & - & - & - & $31.25-125$ & 62.5 & 125 \\
\hline $\begin{array}{l}\text { Amoxicillin + } \\
\text { Sulbactam }\end{array}$ & 8.3 & 25 & 16.7 & - & - & 33.3 & 16.7 & - & - & $1.95-125$ & 31.25 & 62.5 \\
\hline Oxacillin & 66.7 & 33.3 & - & - & - & - & - & - & - & $62.5-125$ & 125 & 125 \\
\hline
\end{tabular}

Numbers indicate percentage of isolates. Numbers in bold indicate percentage of isolates with MIC values greater than the highest concentration in the dilution range and vertical line indicate clinical breakpoints, with the value to the right of the line being susceptible and those to the left being resistant. $\mathrm{MIC}_{50}$ and $\mathrm{MIC}_{90}$ values are concentrations at which $\geq 50 \%$ and $\geq 90 \%$ of isolates are inhibited respectively.

Table 3. Primer sequences, amplicon size and target genes.

\begin{tabular}{llcc}
\hline Bacteria & Primer sequence (5'-3') & $\begin{array}{c}\text { Amplicon size (bp) and } \\
\text { reference }\end{array}$ & $\begin{array}{c}\text { Target } \\
\text { gene }\end{array}$ \\
\hline Methicillin & AAA ATC GAT GGT AAA GGT TGG C & 533 & \\
resistant & ACT TCT GCA GTA CCG GAT TTG C & (Lee, 2003) & mecA \\
S. aureus & ACT TCA ACA CCT GCT GCT TTC & 173 & blaZ \\
& TGA CCA CTT TTA TCA GCA ACC & (Martineau et al., 2000) & \\
& ATC ATT AGG TAA AAT GTC TGG ACA TGA TCC A & 433 \\
& GCA TCA AST GTA TTG GAT AGC AAA AGC & (Lina et al., 1999) & PVL \\
\hline
\end{tabular}

cent) and oxytetracycline (41.7 per cent) (Table 1$)$.

Methicillin resistant $S$. aureus: The incidence of MRSA mastitis by MRSA Alert kit test was 10.34 per cent (12/116). Twelve $S$. aureus samples were positive for clot and color change from yellowish to red confirm the MRSA.

Minimum inhibitory concentration (MIC): Minimum inhibitory concentration of different antibiotics for
MRSA isolates are presented in Table 2.

The MIC breakpoints for gentamicin, oxytetracycline, ceftriaxone, enrofloxcain, amoxicillin, penicillin $\mathrm{G}$, amoxicillin + sulbactam and oxacillin were $8,8,4, \geq$ $0.5,0.25,0.12,4$, and $2 \mu \mathrm{g} / \mathrm{ml}$ for MRSA respectively (Febler et al., 2010).

Based on the breakpoints the result indicate that MRSA is sensitive to gentamicin (24.9 percent), 


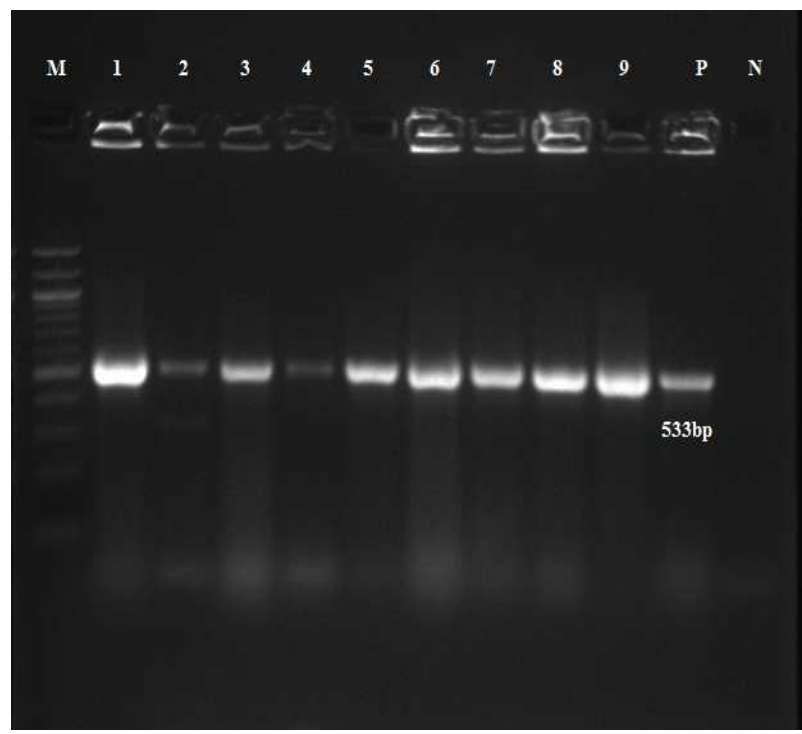

Fig. 1. $P C R$ results of mec A gene of MRSA. $M-100 \mathrm{bp} \mathrm{ladder,}$ Lane 1-9 - Test samples, P-Positive control, $N$ - Negative control.

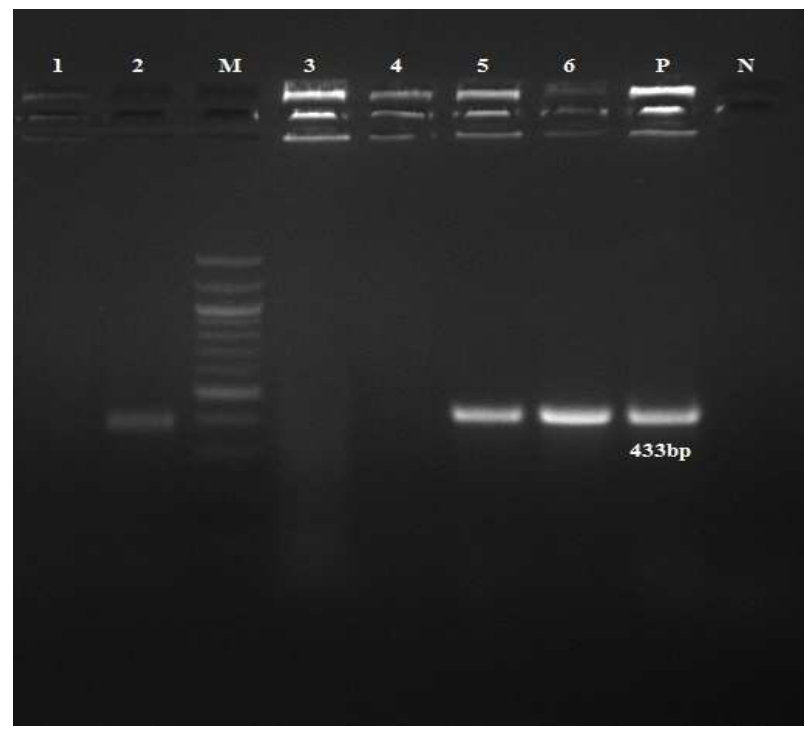

Fig.3. $P C R$ results of $P V L$ gene of MRSA. $M-100 \mathrm{bp} \mathrm{ladder,}$ Lane 1-6 - Test Samples, P-Positive control, N-Negative control.

enrofloxcain (8.3 percent), amoxicillin + sulbactam (50 percent), ceftriaxone (8.3 percent) and resistant to amoxicillin (100 per cent), oxytetracycline (73.4 percent), penicillin $\mathrm{G}$ (100 per cent) and oxacillin (100 percent) and this concur with findings of (Febler et al., 2010).

Molecular characterization of the $S$. aureus and their resistance genes: The incidence of MRSA mastitis by targeting specific gene mecA (Fig.1) and blaZ (Fig.2) in the study was 10.34 per cent (12/116). 7 out of 12 MRSA strains showed amplification of PVL genes (Fig.3).

\section{DISCUSSION}

Antibiotic resistant bacteria pose a growing problem of concern, worldwide. Mastitis is the most common

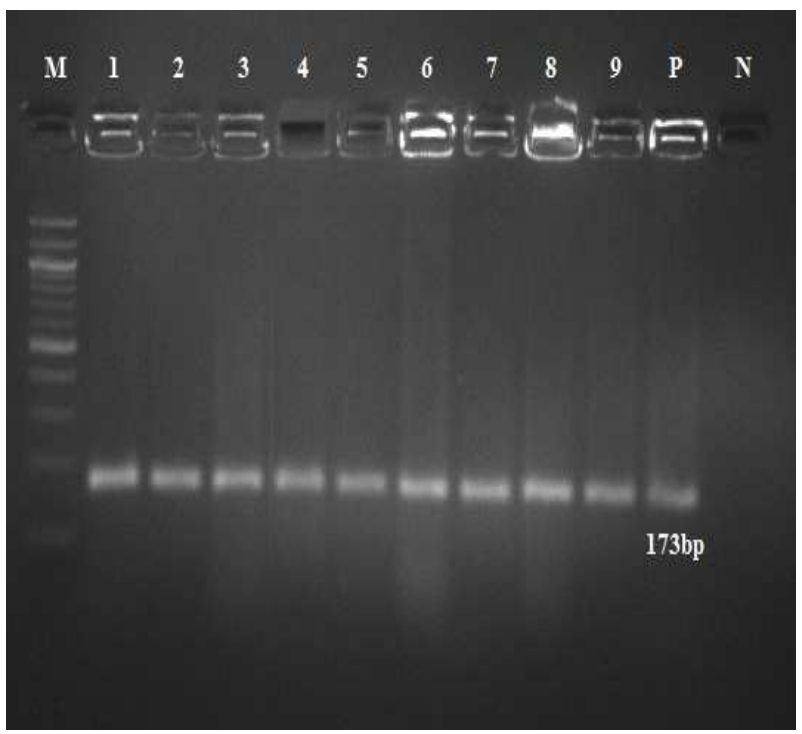

Fig. 2. $P C R$ results of blaZ gene of MRSA. $M-100 b p$ ladder, Lane 1-9 - Test samples, $P$ - Positive control, $N$ - Negative control.

cause for antibiotic use in dairy herds. Effectiveness of current treatments and ability to control infectious diseases in both animals and humans may become hazardous. However, improper use of antibiotics creates problems such as the emergence of bacterial resistance to antibiotics (Chambers, 1997). One of these problems, the occurrence of methicillin resistance, has been observed frequently in recent years (Febler et al., 2010). Therefore, infections by MRSA require rapid and accurate diagnosis for elimination at an early stage, because these strains can cause severe damage to infected sites and may be widespread in the environment (Lee et al., 2004). In most routine microbiological settings, the detection of methicillin resistance among staphylococcal isolates is based on phenotypic assays such as the disk diffusion test and MIC determination. Genetic confirmation of positive findings based on detection of the mecA gene has also been reported (Udo et al., 1996).

MRSA strains were multi-drug resistant which might be due to production of betalactamase and PBP2a (penicillin binding protein) (Kumar et al., 2010). Indiscriminate use of antibiotics and intramammary preparations used by the owner without the prescription of the veterinarian is attributed to be one of the reasons for increasing incidence of these strains.

MRSA alert kit test was found to be useful in the detection of methicillin resistance in $\beta$ lactamase resistance $S$. aureus (Selepak and Witebsky, 1985).

The MIC break point for pencillin G, oxytetracycline, amoxicillin and oxacillin in MRSA mastitis in the present study was $0.12,8,0.25$ and $2 \mu \mathrm{g} / \mathrm{mL}$. Hence, they were considered as resistance. The high resistance of pencillin G, oxytetracycline, amoxicillin and oxacillin in MRSA mastitis in the present study could be attributed to the indiscriminate use of these drugs and intramammary preparations (Cloxacillin) used by 
the owner without the prescription of the veterinarian. Enrofloxacin was found most effective against MRSA (Kenar et al., 2012) and results obtained are similar to those obtained by the above said authors. All MRSA were resistant to members of the penicillin family, such as ampicillin, oxacillin and penicillin.

Detection of mecA and blaZ gene by PCR was gold standard test for confirmation of methicillin resistance (Loeffler and Lloyd, 2010). This high incidence in the present study might be due to indiscriminate use of antibiotics and intramammary preparations used by the owner without the prescription of the veterinarian.

MRSA from bovine hosts could also contain PVL genes (Fig.3). Since cattle has a close contact with the cattle rearing community. MRSA from an animal reservoir has entered the human population and it is responsible for causing $>20 \%$ of all MRSA infections (Van Loo et al. 2007). Avoiding routine antimicrobial use in food animals, to decrease selection pressures, might decrease the prevalence of MRSA among cows.

\section{Conclusion}

The incidence of MRSA mastitis was 10.34 per cent. MRSA isolates were found sensitive to gentamicin, enrofloxcain, amoxicillin+sulbactam, ceftriaxone and resistant to penicillin $\mathrm{G}$, amoxicillin, oxytetracycline and oxacillin and were Multidrug resistance. MRSA alert kit test and targeting mec $\mathrm{A}$ and bla $\mathrm{Z}$ genes were useful in the confirmation of MRSA. The study suggests a high risk for transmission of AMR bacteria from milk or milk products to human populations.

\section{REFERENCES}

Blaine, K. P., Tuohy, M. J., Wilson, D., Procop, G.W., Tisch, D. J., Shrestha, N.K. and Hall, G.S. (2010). Progression to bacteremia in critical care patients colonized with methicillin - resistant Staphylococcus aureus expressing Panton-Valentine leukocidin. Diagnostic Microbiology of Infectious Disease, 68(1): 28-33.

Chambers, H,F. (1997). Methicillin resistance in staphylococci: Molecular and biochemical basis and clinical implications. Clinical Microbiology Review, 10: 781 791.

Clinical and Laboratory Standard Institute (CLSI). (2008). Performance standards for antimicrobial disk and dilution susceptibility tests for bacteria isolated from Animals. pp. 65-72. In: Approved standard M31-A3 (3rd edn). Clinical and Laboratory Standards Institute, Wayne, PA.

Febler, A., Scott, C., Kadlec, K., Ehricht, R., Monecke, S. and Schwarz, S. (2010). Characterization of methicillin -resistant Staphylococcus aureus ST398 from cases of bovine mastitis. Journal of Antimicrobial Chemotherapy, 65(4): 619-25.

Juhász-Kaszanyitzky, E., Janosi, S., Somogyi, P., Dan, A., Bloois, L. G. and Wagenaar, J. A. (2007). MRSA transmission between cows and humans. Emerging Infectious Disease, 13: 630-632.

Kenar, B., Kuyucuoglu, Y. and Seker, E. (2012). Antibiotic susceptibility of coagulase - negative staphylococci isolated from bovine subclinical mastitis in Turkey. Pakistan Veterinary Journal, 32: 390-393.

Kumar, R., Yadav, B. R. and Singh, R. S. (2010). Genetic determinants of antibiotic resistance in Staphylococcus aureus isolates from milk of mastitic crossbred cattle. Current Microbiology, 60: 379-386.

Kumar, R., Yadav, B. R. and Singh, R. S. (2011). Antibiotic resistance and pathogenicity factors in Staphylococcus aureus isolated from mastitic Sahiwal cattle. Journal of Biological Sciences, 36: 175-188.

Lee, J. H. (2003). Methicillin (oxacillin)-resistant Staphylococcus aureus strains isolated from major food animals and their potential transmission to humans. Applied Environmental Microbiology, 69: 6489-6494.

Lee, J. H., Jeong, J. M., Park, Y. H., Choi, S. S., Kim, Y. H., Chae, J. S., Moon, J. S., Kim, S. and Eo, S. K. (2004). Evaluation of the methicillin-resistant Staphylococcus aureus (MRSA)-screen latex agglutination test for detection of MRSA of animal origin. Journal of Clinical Microbiology, 42:2780-2782.

Lina, G., Piemont, Y., Godail-Gamot, F., Bes, M., Peter, M. O., Gauduchon, V. (1999). Involvement of pantonvalentine leukocidin-producing Staphylococcus aureus in primary skin infections and pneumonia. Clinical Infectious Disease, 29:1128-32.

Loeffler, A. and Lloyd, D. H. (2010). Companion animals: a reservoir for methicillin - resistant Staphylococcus aureus in the community?. Epidemiology of Infection, 138(5): 595-605.

Martineau, F., Picard, F. J., Lansac, N., Ménard, C., Roy, P. H., Ouellette, M. and Bergeron, M. G. (2000). Correlation between the resistance genotype determined by multiplex PCR assays and the antibiotic susceptibility patterns of Staphylococcus aureus and Staphylococcus epidermidis. Antimicrobial Agents Chemotherapy, 44: 231-238.

Olsen, J. E., Christensen, H. and Aarestrup, F. M. (2006). Diversity and evolution of blaZ from Staphylococcus aureus and coagulase negative Staphylococci. Journal of Antimicrobial Chemotherapy, 57: 450-460.

Piddock, L. J. V. (1996). Does the use of antimicrobial agents in veterinary medicine and animal husbandry select antibiotic resistant bacteria that infect man and compromise antimicrobial chemotherapy? Journal of Antimicrobial Chemotherapy, 38: 1-3.

Rankin, S., Roberts, S., O'shea, K., Maloney, D., Lorenzo, M. and Benson, C. E. (2005). Panton valentine leukocidin (PVL) toxin positive MRSA strains isolated from companion animals. Veterinary Microbiology, 108: 145-8.

Radostits, O. M., Blood, D. C. and Gay, G. C. (2008). Veterinary Medicine. A Textbook of the Diseases of cattle, sheep, pigs, goats and horses. $10^{\text {th }}$ Ed., Bailliare Tindall, London.

Sarker, S. D., Nahar, L. and Kumarasamy, Y. (2007). Microtitre plate-based antibacterial assay incorporating resazurin as an indicator of cell growth, and its application in the in vitro antibacterial screening of phytochemicals. Methods, 42: 321-324.

Selepak, S. T. and Witebsky, F. G. (1985). Inoculum size and lot to lot variation as significant variables in the tube coagulase test for Staphylococcus aureus. Journal of Clinical Microbiology, 22:835-837.

Turutoglu, H., Ercelik, S. and Ozturk, D. (2006). Antibiotic resistance of Staphylococcus aureus and Coagulasenegative Staphylococci isolated from bovine mastitis. 
Bulletin of Veterinary Institute in Pulawy, 50: 41-45.

Udo, E. E., Al-Obaid, I. A., Jacob, L. E. and Chugh, T. D. (1996). Molecular characterization of epidemic ciprofloxacin- and methicillin resistant Staphylococcus aureus strains colonizing patients in an intensive care unit. Journal of Clinical Microbiology, 34: 3242-3244.

Vandenesch, F., Naimi, T., Enright, M. C., Lina, G., Nimmo, G. R. and Hefferman, H. (2003). Community-acquired methicillin-resistant Staphylococcus aureus carrying Panton-Valentine leukocidin genes: worldwide emergence. Emerging Infectious Disease, 9: 978-984.

Van Loo, I., Huijsdens, X., Tiemersma, E., De Neeling, A.,
Van de Sande-Bruinsma, N., Beaujean, D. (2007). Emergence of methicillin-resistant Staphylococcus aureus of animal origin in humans. Emerging Infectious Disease, 13:1834-9.

Witte, W., Strommenger, B., Stanek, C. and Cuny, C. (2007). Methicillin-resistant Staphylococcus aureus ST398 in humans and animals, central Europe. Emerging Infectious Disease, 13: 255-258.

Yugueros, J., Temprano, A., Sanchez, M., Luengo, J. and Naharro, G. (2001). Identification of Staphylococcus spp. by PCR-restriction fragment length polymorphism of gap gene. Journal of Clinical Microbiology, 39:3693-3695 